\title{
高速铁路对中心城市航空客运市场的空间影响 基于人均时间价值视角
}

\author{
王绍博 ${ }^{1}$, 郭建科 $2^{*}$, 罗小龙 ${ }^{1}$, 顾宗倪 ${ }^{1}$ \\ (1. 南京大学建筑与城市规划学院, 南京 210093 ; \\ 2. 辽宁师范大学海洋经济与可持续发展研究中心,辽宁大连 116029)
}

\begin{abstract}
摘 要: 揭示高铁对中国航空客运市场影响的空间分异特征, 对于针对性协调 2 种交通方式的发展具有重要参考价 值。运用标准差粗圆和交通综合效用分析方法, 对中国中心城市高铁、航空客运市场实际发展现状及空间竞合分 异特征进行分析。结果发现: (1) 高铁、航空客运市场均形成以武汉为重心点的空间发展格局; 与高铁客运市场相 比, 航空客运市场区域发展更加均衡; 与东西部中心城市相比, 中部中心城市旅客出行选乘高铁的概率更高。(2) 人均时间价值与高铁优势距呈反比,优势距的不同使各中心城市高铁、航空客运市场范围存在明显的空间分异特 征; 基于交通出行综合效用视角, 中国大多数中心城市间的交往, 航空出行依旧是最好的选择。(3) 高铁对航空客 运市场的影响存在明显的空间分异特征。中部大部分中心城市受影响最大, 是协调高铁、航空发展的关键区域; 西 部地区受交通区位条件及高铁发展滞后的影响, 中心城市间交往时飞机仍是旅客主要的出行方式, 在航空主导优 势区依旧存在一定的市场空白。
\end{abstract}

关 键 词: 高速铁路; 航空; 人均时间价值; 竞合; 空间分异

中心城市作为区域旅客集散输送的交通枢纽, 能够在一定程度上充分发挥高速铁路大通道大量 旅客快速输送的优势(钟业喜等, 2015), 进而使其在 高铁规划中取得优先发展权。截至2015 年, 中国高 速铁路总规模突破 4 万 $\mathrm{km}$ (郭建科等, 2016), 已基 本实现中心城市的全部覆盖。高铁的快速发展对 中心城市产生了诸多积极影响: 拉近了中心城市间 的时空距离; 强化了中心城市对周边区域的辐射带 动能力; 促进了不同都市圈之间的交流与合作; 加 快了区域“同城化”的发展步伐。然而, 新交通方式 的出现, 会不可避免地冲击原有运输市场格局。尤
其对于与高铁旅客输送优势相当的航空产业, 必然 会受到高铁发展带来的市场排挤效应。统计发现， 高铁运行后, 中国部分地区航线(北京-徐州、天津一 南京、郑州-西安)出现停航现象(孙枫等, 2017)。因 此, 揭示高铁运行后航空客运市场出现的新变化、 新特征, 对于打造一体衔接的快速交通体系具有十 分重要的理论参考价值。

高铁作为交通系统中的重要组成部分, 其开通 对于其他交通方式的影响, 尤其是对于航空客运的 影响, 吸引了国内外学者的普遍关注。研究内容主 要分为以下几个方面: (1) 各交通方式运输属性的对

收稿日期: 2018-12-11; 修订日期: 2019-05-13。

基金资助 : 国家自然科学基金项目(41871112,41471133); 城市群系统演化与可持续发展的决策模拟研究北京市重点实验室 2019 年度开放基金(MCR2019QN16)。[Foundation: National Natural Science Foundation of China, No. 41871112 and 41471133; the Beijing Key Laboratory of Megaregions Sustainable Development Modelling, Capital University of Economics and Business, No. MCR2019QN16. ]

第一作者简介: 王绍博(1990-), 男, 山东东营人, 博士生, 主要从事交通可达性、交通经济学、城乡规划方面研究。 E-mail: 18840817152@163.com

*通信作者简介: 郭建科(1980-), 男, 山西长治人, 博士, 教授, 博士生导师, 主要从事交通运输与物流组织方面研究。 E-mail: gjianke@126.com

引用格式: 王绍博, 郭建科, 罗小龙, 等. 2019. 高速铁路对中心城市航空客运市场的空间影响: 基于人均时间价值视角 [J]. 地理科学进展, 38 (11): 1665-1674. [Wang S B, Guo J K, Luo X L, et al. 2019. Spatial differentiation of the impact of high-speed rail on aviation passenger market in central cities of China. Progress in Geography, 38(11): 1665-1674. ] DOI: 10.18306/dlkxjz.2019.11.002 
比分析。基于旅行者需求视角,从安全性、经济性、 舒适性、便利性等角度比较不同交通方式运输特征, 进而推断旅行者选择偏好(Concepción et al, 2007; 梁雪松, 2010; Yang, Burghouwt et al, 2018)。(2) 基 于优势距探讨各交通方式的运输市场范围(Oskar, 2008; 彭峥等, 2009; 郭春江, 2010; Yang, Dobruszkes et al, 2018)。例如 Oskar(2008)研究发现, 小轿 车、长途汽车主要适合短途运输市场, 而高铁、飞机 在中长途运输市场优势更加明显; 彭峥等(2009)、郭 春江(2010)基于时间成本、经济成本、环境成本等因 素构建计量模型推导了各交通方式的市场分界线。 (3) 采取实地考察方式统计某交通方式开通后其他 交通方式客流量变化(Frédéric, 2011; 丁金学等, 2013; 王姣娥等, 2013)。例如研究发现在日本、韩 国、德国、西班牙等地, 高速铁路吸引了航空、公路等 其他交通方式客源总量的 10\% 30\%(Vickerman, 1997; Givoni, 2006; Park et al, 2006; 王绍博等, 2019)。

综上可知:第一, 目前高铁与航空产业的竞合 多以定性分析为主, 或者采用实地调研数据统计分 析, 而通过函数模型构建定量测度两者相互影响的 研究相对较少; 第二, 多基于经济学、管理学视角分 析部分地区、线路高铁对航空运输市场造成的整体 影响, 缺乏地理学视角下高铁对航空市场影响的空 间分异特征研究; 第三, 忽视不同地区经济发展基 础不同所造成的人均时间价值的差异, 采用同一标 准测度高铁、航空优势距离, 与现实情况差别较 大。基于此, 本文运用标准差陏圆分析方法呈现中 国中心城市高铁、航空客运市场发展的空间分布特 征, 然后基于各中心城市人均时间价值的现实状 况, 运用交通方式综合效应模型, 识别各中心城市 高铁、航空优势距, 进而揭示中国中心城市高铁与 航空客运市场的空间竞合格局, 以期为中国快速交 通体系实现 “网络化布局、智能化管理、一体化服 务、绿色化发展”的目标提供数据参考。

需要说明的是: 本文以中心城市为例探讨高铁 对航空市场的挤出效应主要基于以下考虑: 相关研 究(王姣娥等, 2013)表明大城市是航空与高铁竞争 的主要市场, 数据统计也发现, 中国中心城市(直辖 市、省会城市、副省级城市)的航空旅客吞吐量占全 国航空旅客吞吐总量的比重达 $70.7 \%$, 中心城市高 铁通勤频次占全国高铁通勤总频次的 $51.1 \%$ 。可见 中心城市高铁、航空客运市场协调发展是实现中国
快速交通运输体系构建的关键。基于此, 文章主要 以直辖市、省会城市、副省级城市为例, 探究高铁对 于航空客运市场的空间影响。

\section{1 模型构建与数据处理}

\section{1 标准差椭圆}

本文将采用标准差椭圆对中心城市高铁、航空 发展的空间分布格局进行呈现,标准差椭圆有 5 大 基本要素(方叶林等, 2013; 王绍博等, 2016; 王绍博 等, 2017): 中心点、长半轴、短半轴、展布范围和方 位角。中心点表示地理要素空间分布的相对位置, 方位角表示发展的主趋势方向,长半轴代表地理要 素在主趋势方向上的离散程度,短半轴代表地理要 素在次要方向上的离散程度。识别高铁、航空椭圆 基本要素的不同对于正确认识中国中心城市航空、 高铁发展的空间分异特征具有重要作用。

\section{2 综合效用函数}

旅客在选乘某种交通方式过程中所能获得的 最大满足感即为旅行者的出行效用, 是交通工具在 经济、快捷、舒适、便利和安全等多种属性下的集中 体现。

经济性 $(E)$ 是指旅行者选乘某交通方式由出发 地到目的地整个旅途中所需要向服务商提供的现 金费用支出, 它是整个旅途花销的最直接表现; 快 捷性 $(Q)$ 是指旅行者选乘某交通方式由出发地到目 的地整个旅途中所耗费的时间,它是旅客在选乘交 通方式时重要的参考依据; 舒适性 $(M)$ 是指旅行者 在旅行过程中不因时间过长而产生旅途疲劳感; 便 利性 $(F)$ 是指旅行者非在途所耗费的时间, 它主要包 括购票、安检、候车等过程中耗费的时间; 安全性 $(S)$ 最直接的体现是事故发生率。与其他指标相比, 安 全性 $(S)$ 相对独立, 事故率越高, 该交通方式的综合 效用将越打折扣。本文采用加法与乘法相结合的 方式构建出行效用关系式(孙枫等, 2017):

$$
U=\sum_{i=1}^{n}\left(\alpha E_{i}^{-1}+\beta Q_{i}^{-1}+\gamma M_{i}^{-1}+\delta F_{i}^{-1}\right) \times \varepsilon S_{i}
$$

式中: $U$ 代表某中心城市高铁或航空出行的综合效 用; $n$ 代表该中心城市 $i$ 通航城市的数量; $E 、 Q 、 M 、 F$ 和 $S$ 分别为经济、快捷、舒适、便利和安全性指标; $\alpha$ 、 $\beta 、 \gamma 、 \delta$ 和 $\varepsilon$ 为各指标对整体出行效用的影响权重, 可 通过极大似然估计法算出, 基于已有研究, 分别赋 值 $0.49 、 0.28 、 0.12 、 0.11$ 和 1 (孙枫等, 2017 )。当 $U_{\text {高铁 }}$ 


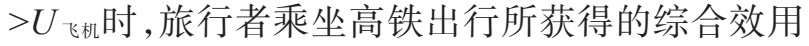
更高; 反之, 选择航空出行更高。具体来看:

经济性指标由交通方式单位距离票价与通行 距离的乘积获得。关于高铁、航空票价赋值问题: 高铁、航空均存在不同等级票价, 且航空存在折扣 票, 但相关票价占比情况不得而知, 因此现有研究 多采用国家发改委及《民航国内运价改革方案》中 定价标准赋值(丁金学等, 2013; 孙枫等, 2017), 本文 同样基于此进行。其中, $G$ 字头, 时速 $300 \mathrm{~km}$ 及以 上的高铁约为 0.48 元 $/($ 人 $\cdot \mathrm{km})$; 航空票价为 0.75 元 $/$ $(人 \cdot \mathrm{km})$ (卢婉婉, 2015)。 $I_{i}$ 代表高铁或航空的定价、 $D$ 代表 2 个中心城市间的距离,则:

$$
E=I_{i} \times D
$$

快捷性指标由整个旅途所耗费的时间与人均 时间价值的乘积获得。整个旅途时间共分为 2 部 分: 旅客到机场、高铁站点的时间 $(t)$; 站点与站点之 间的时间 $(T)$ 。 $A$ 为人均时间价值, 是经济学中的一 个概念, 测度方式主要有 3 种: 生产法、收人法、非集 计模型, 本文主要从收人法方面进行测度, 由各中 心城市 2015 年人均 GDP 与全年工作时间的比值获 得(宗芳等, 2009; 孙枫等, 2017)。时间指标 $(t)$ 基于 GIS 操作平台中最短路径分析模块获取旅客到站点 的可达性时间; 航空、高铁站点到站点间的时间 $(T)$ 分别基于同程旅游网(https://www.ly.com/)、12306 网获得(https://www.12306.cn)。

$$
Q=(T+t) \times A
$$

舒适性指标测度已相对完善:

$$
M=\frac{J \times A}{1+a \times \mathrm{e}^{-b \times T}}
$$

式中: $J$ 为极限疲劳恢复期, 通过旅行疲劳恢复曲线 测得, 赋值 16(郭春江, 2010); $a 、 b$ 为阻滞系数, 借鉴 以往研究, 分别赋值 69、0.25(郭春江, 2010; 丁金学 等, 2013; 孙枫等, 2017)。

便利性指标由购票、安检、候车等过程中耗费 的时间与人均时间价值的乘积获得。机场安检相 对严格, 高铁站点客流量大使购票、检票时间相对 较长。调查问卷发现, 航空、高铁站点购票、安检、 候车等过程中耗费的时间分别在 $1 \mathrm{~h} 、 0.75 \mathrm{~h}$ 左右。

安全性指标。考虑到高铁、航空运输事故发生 率均较低, 安全性系数均较高, 因此, 高铁、飞机安 全性指标均取 1(孙枫等, 2017)。

\section{3 数据来源}

旅客到站点的时间基于 ArcGIS 10.0 操作平台 中最短分析模块获取, 采用全国 2015 年道路交通网
络(1:300万交通网络图)。依据《中华人民共和国公 路工程技术标准》(JTGB-2014)的要求对各等级路 网进行赋值: 高速公路 $120 \mathrm{~km} / \mathrm{h}$; 国道 $100 \mathrm{~km} / \mathrm{h}$; 省 道 $80 \mathrm{~km} / \mathrm{h}$; 县道及其他道路 $40 \mathrm{~km} / \mathrm{h}$; 铁路 $90 \mathrm{~km} / \mathrm{h}$; 航线相关数据由同程旅游网查询获得; 高铁相关数 据由 12306 网查询获得; 经济类指标来源于《2016 年中国城市统计年鉴》。本文的研究对象中心城市 主要涵盖各省会城市及副省级城市, 考虑到拉萨、 银川暂未开通高铁, 海口高铁并未与大陆高铁网络 相连, 本文未对此 3 个城市做相关分析, 另外, 港澳 台地区城市因数据获取困难也未考虑, 因此, 本文 涉及中心城市数量共 33 个。

需要说明的是: (1) 为方便起见, 旅客所在地以 城市节点代替, 不考虑中途换乘所耗费的时间。(2) 目前高铁主要是客运职能, 因此本文仅基于客运视 角探究高铁与航空竞争的空间分异特征。(3)以往 研究发现, 目前各城市高铁、航空客座率均存在严 重空置现象(徐广岩, 2016), 因此高铁、航空运输市 场存在供大于需的问题,在此情况下,旅行者对 2 种 交通方式的选择偏好成为它们竞争的关键。因此, 文章从旅客出行角度探究高铁、航空市场竞争具有 一定的现实意义。

\section{2 中心城市高铁、航空客运市场发展 的空间格局}

根据交通运输部数据统计, 全国高铁客运量占 铁路客运总量的比例达 4 成左右。然而对中心城市 而言, 高铁网络和相关基础设施建设已相对完善, 高铁客运量占铁路客运总量会更高。梳理各中心 城市高铁运行频次占该地区铁路总运行频次的比 重发现(表 1), 中国 62.5\%的中心城市高铁运行频次 比重达 $80 \%$ 以上, 其中, 福州、厦门、长沙、宁波、深 圳、南京、广州、武汉等高铁运行频次占比已经超过 $90 \%$; 其余中心城市除乌鲁木齐外, 高铁运行频次 占地区铁路总运行频次的比重也均在 $50 \%$ 以上。 汇总发现, 中国所有中心城市的高铁运行频次占中 心城市铁路总运行频次的比重为 $83.4 \%$, 可见高铁 已经成为中心城市铁路运输的重要组成部分。

因目前统计年鉴尚未对各城市高铁客运量、机 场国内客运量做详细统计, 现有研究在评估高铁、 航空客流情况时多以相应站点高铁、航空的运行频 次(孟德友等, 2017; 蒋海兵等, 2018)来表示, 不能很 
表 1 中心城市日均高铁运行频次及铁路总运行频次统计

Tab.1 Daily frequency of high-speed trains and all trains of central cities

\begin{tabular}{|c|c|c|c|c|c|c|c|}
\hline 中心城市 & 高铁日均运行频次 & 铁路总频次 & 高铁比重 & 中心城市 & 高铁日均运行频次 & 铁路总频次 & 高铁比重 \\
\hline 福州 & 337 & 349 & 0.97 & 合肥 & 278 & 333 & 0.83 \\
\hline 厦门 & 311 & 323 & 0.96 & 青岛 & 146 & 182 & 0.80 \\
\hline 长沙 & 702 & 756 & 0.93 & 南昌 & 286 & 361 & 0.79 \\
\hline 深圳 & 588 & 634 & 0.93 & 西安 & 357 & 454 & 0.79 \\
\hline 宁波 & 201 & 217 & 0.93 & 大连 & 119 & 160 & 0.74 \\
\hline 南京 & 657 & 726 & 0.90 & 长春 & 239 & 323 & 0.74 \\
\hline 广州 & 962 & 1068 & 0.90 & 北京 & 605 & 824 & 0.73 \\
\hline 武汉 & 633 & 703 & 0.90 & 石家庄 & 286 & 411 & 0.70 \\
\hline 济南 & 443 & 500 & 0.89 & 西宁 & 57 & 84 & 0.68 \\
\hline 成都 & 416 & 470 & 0.89 & 沈阳 & 290 & 447 & 0.65 \\
\hline 上海 & 748 & 846 & 0.88 & 兰州 & 162 & 252 & 0.64 \\
\hline 南宁 & 332 & 380 & 0.87 & 昆明 & 141 & 230 & 0.61 \\
\hline 杭州 & 497 & 574 & 0.87 & 太原 & 122 & 221 & 0.55 \\
\hline 郑州 & 474 & 554 & 0.86 & 哈尔滨 & 183 & 336 & 0.54 \\
\hline 天津 & 548 & 641 & 0.85 & 呼和浩特 & 70 & 137 & 0.51 \\
\hline 重庆 & 308 & 366 & 0.84 & 乌鲁木齐 & 46 & 135 & 0.34 \\
\hline 贵阳 & 228 & 272 & 0.84 & & & & \\
\hline
\end{tabular}

好地反映高铁、航空实际客运规模。为更好地反映 各中心城市高铁、航空(国内)运输市场空间分布格 局, 本文以各中心城市高铁运行频次占地区铁路总 运行频次的比重与地区铁路客运总量的乘积、机场 的国内航线运行频次占地区总航线频次的比重与 地区航空客运量的乘积来分别预估各中心城市的 高铁、航空(国内)客运量,虽然存在一定的误差,但 在一定程度上可反映高铁、航空的客运量规模。然 后基于标准差粗圆分析方法, 从运输市场发展中心 点、方位角、展布范围等多角度分析中国中心城市 高铁、航空(国内)客运市场的现实发展状况。结果 如下:

(1) 高铁、航空客运市场整体发展格局方面(图 1)。从重心点来看, 中国中心城市高铁、航空客运 市场目前均形成以武汉为重心点的空间发展格局; 从旋转方位角来看, 高铁客运市场偏转角度为北偏 东 $18.12^{\circ}$, 航空客运市场偏转角度为北偏东 $19.49^{\circ}$, 说明中国东部沿海地区快速交通网络发展明显好 于中西部地区; 从椭圆展布范围来看, 与高铁运输 市场相比,航空客运市场东西方向伸展程度明显高 于高铁客运市场,椭圆形状更近似圆形, 说明中国 中心城市航空客运市场区域发展的均衡性要明显 好于高铁客运市场; 从椭圆南北伸展来看, 高铁椭 圆相对偏北部、航空椭圆相对偏南,说明中国北部

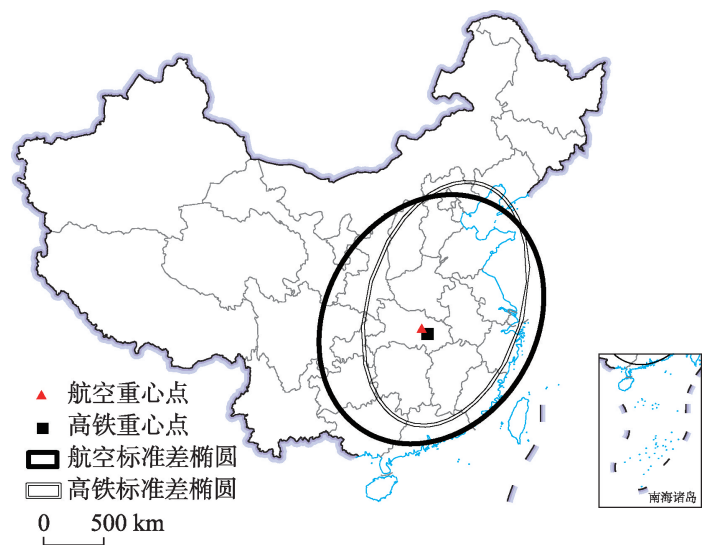

注:本图基于自然资源部标准地图服务网站下载的审图 号为 GS(2019)1652 号的标准地图制作，底图无修改。下同。

图 1 高铁、航空客运市场发展空间分布格局

Fig.1 Spatial distribution pattern of high-speed rail and aviation passenger flight markets

高铁运输市场的发展相对好于南部地区,南部航空 客运市场的发展要相对好于北部。从两椭圆重叠 区域可以看出,中国东、中部许多中心城市高铁、航 空发展优势均较为明显。

(2) 高铁、航空客运量对比可侧面反映该地区 开展高铁运输的相对优势(图 2)。具体来看,中部区 域中心城市高铁通行优势明显高于航空运输, 例如 武汉、郑州、济南、合肥、长春、沈阳等中部中心城市 高铁客运总量与航空客运总量的比值在 5 倍以上; 


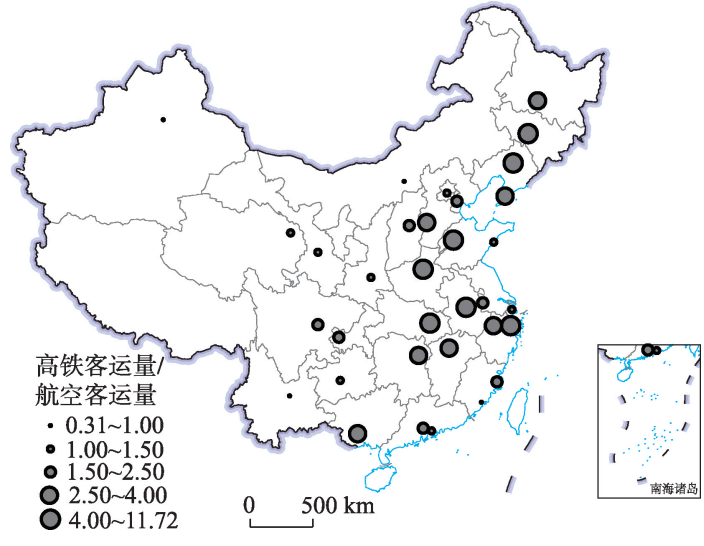

图 2 高铁、航空客运量对比空间分布

Fig.2 Spatial distribution of comparative value of high-speed rail and aviation passenger flights

其余大部分中部中心城市的比值也基本在 2 3 倍之 间。对于北京、上海等国际性航空枢纽城市而言, 航线密集性及服务设施的完善性使得这些城市高 铁、航空年运量基本相同, 比值在 1 左右, 2 种交通 方式运输优势基本相当。而对于周边区域许多中 心城市,受地理区位及高铁目前发展不完善的影 响,航空出行依旧是最好的选择。其中,厦门、乌鲁 木齐、昆明高铁与航空比值低于 1 。

(3) 各中心城市高铁、航空客运量与本地区常 住人口规模的比值可侧面反映中心城市人均高铁、 航空年出行频次(图 3)。整体来看,对于中心城市而 言, 人均高铁出行频次在 4 5 次, 人均航空出行频次 在 2 3 次。其中, 武汉年人均高铁出行频次最高 (15.55), 是高铁运输发展的重要区域; 深圳年人均 航空出行频次最高(13.50), 是航空运输发展的重要 区域。具体来看,中国中心城市高铁、航空出行频 次存在明显的空间分异特征: 年人均高铁出行频次
基本呈现由东向西逐步递减的特征,东、中、西部中 心城市人均高铁出行频次分别在 5 次以上、3 5 次、 0 2 次。年人均航空出行频次呈现中部低、东西高 的分布格局,东、中、西部中心城市人均航空出行频 次分别在 4 次以上、 $0 \sim 2$ 次、2 4 次。可见,东中部地 区是高铁客运发展的关键区域; 东部沿海及中国周 边部分中心城市是航空客运发展的重要区域。

\section{3 中心城市高铁、航空客运市场的空 间竞争格局}

\section{1 中心城市高铁、航空优势距测度}

中国中心城市经济发展差异明显,地区人均时 间价值呈现明显的空间分异特征。人均时间价值 作为影响旅客出行选择偏好的关键因素, 使得各中 心城市高铁、航空出行的优势距离存在明显差别。 文章首先基于能够表征各城市人均时间价值的经 济指标(人均GDP、居民年末储蓄存款、在岗职工平 均工资、职工平均工资、城镇居民可支配收人、人均 社会消费品零售额), 通过聚类分析将 33 个中心城 市分为 4 档,然后计算各档所涉及城市人均时间价 值的平均值来反映各档中心城市的人均时间价值, 结果如表 2 :一至四档中心城市的人均时间价值分 别为 $52.90 、 35.00 、 28.00 、 17.63$ 元 $/ h$ 。

基于 Matlab 操作平台, 利用 logit 分担模型(孙 枫等, 2017; 丁金学等, 2013),对不同距离条件下高 铁、航空的客运分担率进行分析。结果如图 4: (1) 整 体来看, 随着出行距离的不断增加, 高铁的相对优势 持续减少, 并在一定距离下, 航空运输占据一定市 场; (2) 人均时间价值与高铁优势距呈反比, 随着人
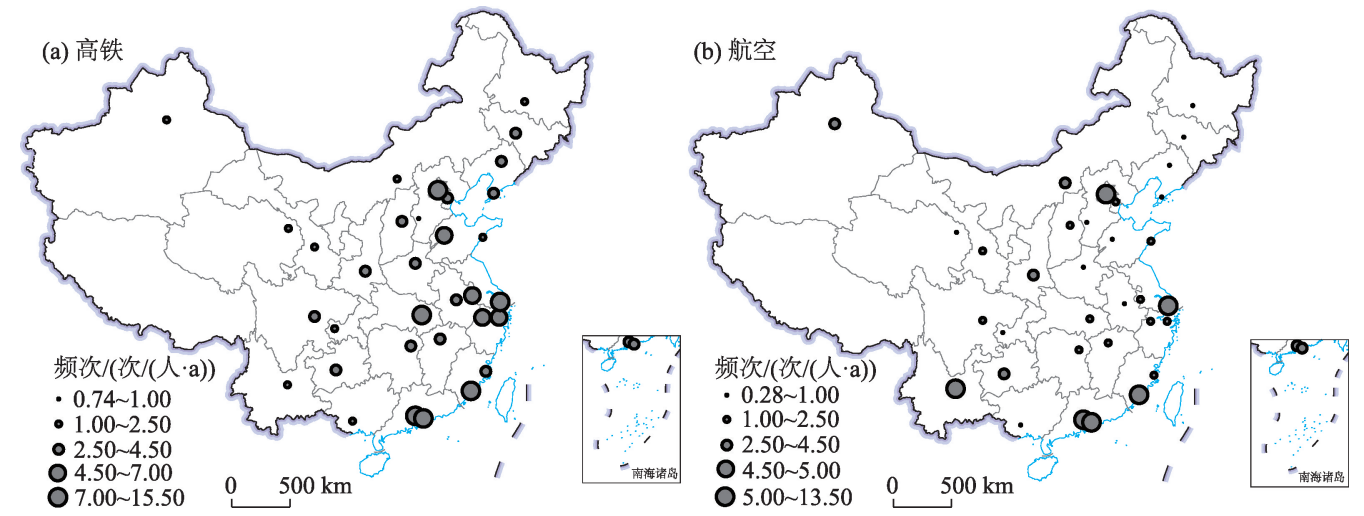

图 3 中心城市高铁、航空人均出行频次空间分布格局

Fig.3 Spatial distribution pattern of the travel frequency per capita of high-speed rail and aviation passenger flights in central cities 
表 2 中心城市人均时间价值统计

Tab.2 Per capita time value statistics of central cities

\begin{tabular}{clc}
\hline 类别 & \multicolumn{1}{c}{ 涉及城市 } & 人均时间价值 \\
\hline 第一档 & 北京、上海、天津 & 52.90 元 $/ \mathrm{h}$ \\
第二档 & 南京、杭州、宁波、济南、青岛、武汉、长春、重庆、沈阳、大连、广州、深圳 & 35.00 元 $/ \mathrm{h}$ \\
第三档 & 哈尔滨、西宁、福州、厦门、郑州、合肥、石家庄、南昌、长沙、西安 & 28.00 元 $/ \mathrm{h}$ \\
第四档 & 昆明、兰州、贵阳、太原、南宁、成都、呼和浩特、乌鲁木齐 & 17.63 元 $/ \mathrm{h}$ \\
\hline
\end{tabular}

注: 人均时间价值由各档涉及中心城市人均时间价值的平均值求得。

(a) 人均时间价值 52.90 元/h

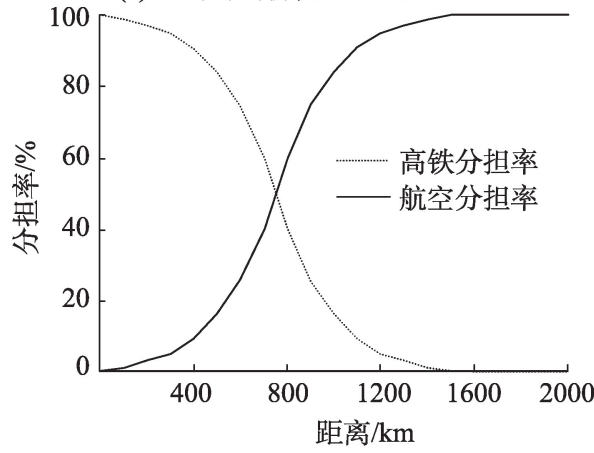

(c) 人均时间价值 28.00 元 $/ \mathrm{h}$

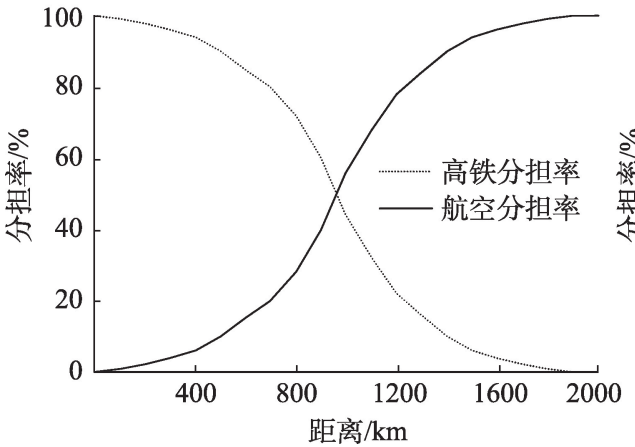

(b) 人均时间价值 35.00 元 $/ \mathrm{h}$

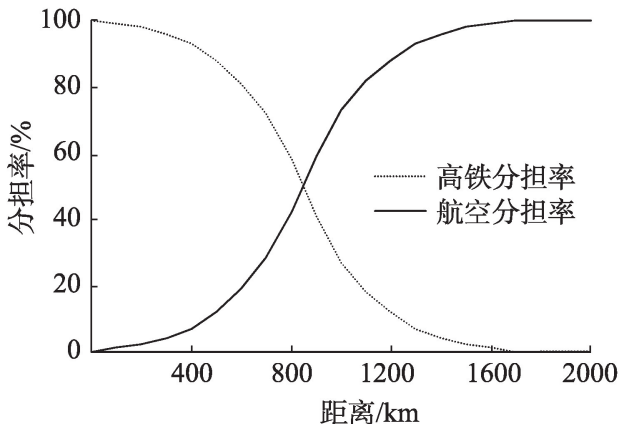

(d) 人均时间价值 17.63 元 $/ \mathrm{h}$

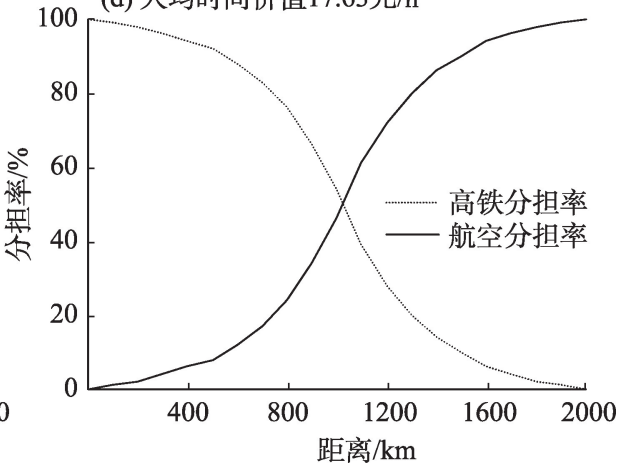

图 4 不同人均时间价值条件下高铁、航空客运分担率

Fig.4 Share ratio of high-speed rail and aviation passenger flights under different per capita time value

均时间价值的增加, 交通出行经济成本压力逐步淡 化,快捷高效成为旅行者交通运输方式选择的重要 考量。梳理不同人均时间价值背景下高铁、航空客 运分担率曲线交点来看,第一至四档所涉及中心城 市高铁出行优势距分别在 780、893、912、998 km 左 右。优势距的不同,对于不同地区的影响不同。

\section{2 高铁对航空运输市场的空间影响}

目前,关于高铁、航空运输市场的划分, 相关研 究(丁金学等, 2013; 孙枫等, 2017; 骆嘉琪等, 2019) 多基于高铁、航空客运市场的分担额进行划分: 将 高铁、航空市场分担额占比超过 $90 \%$ 的称为绝对优 势区; 将市场分担额 70\% 90\%的称为相对优势区, $30 \% \sim 70 \%$ 的称为竞争激烈区。按照以上划分标准，
各档中心城市高铁、航空运输市场划分如下(表 3):

整理各档中心城市高铁、航空运输市场的分界 点(表 3)发现: (1) 对于中国所有中心城市而言, 320 $\mathrm{km}$ 以下属于高铁出行的绝对优势区, $1370 \mathrm{~km}$ 以上 属于航空出行的绝对优势区。(2) 各档中心城市高 铁、航空各市场区范围存在明显的不同:一至四档 中心城市高铁绝对优势区分别在 320、400、480、 $520 \mathrm{~km}$ 以内; 航空绝对优势区分别在 1020、1130、 $1290 、 1370 \mathrm{~km}$ 以上; 竞争激烈区分别在 610 880、 680 910、790 1080、880 1230 km之间; 高铁相对优 势区分别在 320 610、400 680、480 790、520 880 $\mathrm{km}$ 之间; 航空相对优势区分别在 880 1020、910 1130、1080 1290、1230 1370 km之间。基于高铁、 
表 3 各档中心城市高铁、航空运输市场划分

Tab.3 The markets of high-speed rail and aviation passenger flights of each central city

\begin{tabular}{|c|c|c|c|c|c|}
\hline \multirow{2}{*}{ 类别 } & \multicolumn{2}{|c|}{ 绝对优势区 $/ \mathrm{km}$} & \multirow{2}{*}{ 高铁、航空竞争激烈区 $/ \mathrm{km}$} & \multicolumn{2}{|c|}{ 相对优势区 $/ \mathrm{km}$} \\
\hline & 高铁 & 航空 & & 高铁 & 航空 \\
\hline 第一档 & 320 以内 & 1020 以上 & $610 \sim 880$ & $320 \sim 610$ & $880 \sim 1020$ \\
\hline 第二档 & 400 以内 & 1130 以上 & $680 \sim 910$ & $400 \sim 680$ & $910 \sim 1130$ \\
\hline 第三档 & 480 以内 & 1290 以上 & $790 \sim 1080$ & $480 \sim 790$ & $1080 \sim 1290$ \\
\hline 第四档 & 520 以内 & 1370 以上 & $880 \sim 1230$ & $520 \sim 880$ & $1230 \sim 1370$ \\
\hline
\end{tabular}

航空市场的划分, 统计各中心城市高铁绝对优势 区、竞争激烈区、相对优势区航空班次占比情况发 现(表4): 总体来看, 高速铁路的开通对中心城市间 航空线路出行产生一定的影响。其中, 高铁绝对优 势区的航空班次占比 $2.1 \%$; 竞争激烈区的航空班次 占比 $4.5 \%$, 相对优势区的航空班次占比 $5.7 \%$, 航空 绝对优势区占比为 $87.7 \%$ 。具体来看:

(1) 高铁绝对优势区: 该类航空线路主要处于高 铁运行的主导区, 一般高铁 $2 \mathrm{~h}$ 之内可达, 且该区域 内旅客出行选乘高铁的概率超过 $90 \%$ 。梳理各中 心城市该区域现有航空班次占比发现: 57\%的中心 城市该区域航空运行频次占比在 $2 \%$ 以下,但也有 4 个城市(郑州、济南、石家庄、合肥)航空运行频次占 比超过 5\%, 适当压缩该区域航线运行频次, 对于合 理高效配置航空资源具有十分重要的参考价值。 (2) 高铁、航空竞争激烈区: 主要处于高铁、航空综合
出行效用相当区, 旅客出行选乘高铁、航空的概率 基本相当,是 2 种交通方式竞争博亦的重点区域。 梳理该区域现有航空班次占比发现: 中国中心城市 高铁、航空竞争相对严重,42.4\%的中心城市该区域 航空班次占比超过 5\%, 其中, 石家庄、郑州、福州、 武汉、西安、合肥、长沙等中心城市该区域航空班次 占比达 $7.5 \%$ 及以上,该区域高铁、航空协调发展对 于中国中心城市快速交通体系的构建具有重要意 义。而处于中国周边区域的中心城市(乌鲁木齐、 长春、哈尔滨、沈阳、兰州、成都等), 该区域范围内 航空班次占比相对较低, 快速交通运输体系协调性 相对较高。(3) 高铁相对优势区: 该区域范围内, 航 空运行班次占比依旧较高, 占比超过 5\%的中心城 市数量达 21 个,南京、南昌、合肥、郑州、长沙等航空 班次占比超过 $10 \%$, 同样是高铁航空竞争明显的重 要区域。(4)航空绝对优势区:该区域旅客选乘航空

表 4 中心城市各市场区航空班次占比情况统计

Tab.4 Percentage of passenger flights of the central cities in each market

\begin{tabular}{lcccc||ccccc}
\hline \multicolumn{1}{c|}{ 城市 } & $\begin{array}{c}\text { 高铁绝对 } \\
\text { 优势区 }\end{array}$ & 竞争激烈区 & 相对优势区 & $\begin{array}{c}\text { 航空绝对 } \\
\text { 优势区 }\end{array}$ & 城市 & $\begin{array}{c}\text { 高铁绝对 } \\
\text { 优势区 }\end{array}$ & 竞争激烈区 & 相对优势区 & $\begin{array}{c}\text { 航空绝对 } \\
\text { 优势区 }\end{array}$ \\
\hline 北京 & 0.017 & 0.026 & 0.047 & 0.910 & 南昌 & 0.033 & 0.068 & 0.108 & 0.791 \\
成都 & 0.013 & 0.017 & 0.056 & 0.914 & 南京 & 0.041 & 0.053 & 0.105 & 0.801 \\
大连 & 0.007 & 0.032 & 0.031 & 0.930 & 武汉 & 0.027 & 0.081 & 0.054 & 0.838 \\
福州 & 0.008 & 0.077 & 0.113 & 0.802 & 南宁 & 0.015 & 0.046 & 0.051 & 0.888 \\
广州 & 0.028 & 0.051 & 0.050 & 0.871 & 深圳 & 0.017 & 0.047 & 0.018 & 0.918 \\
贵阳 & 0.012 & 0.018 & 0.063 & 0.907 & 厦门 & 0.009 & 0.072 & 0.087 & 0.832 \\
哈尔滨 & 0.011 & 0.013 & 0.009 & 0.967 & 天津 & 0.034 & 0.047 & 0.052 & 0.867 \\
济南 & 0.050 & 0.066 & 0.115 & 0.769 & 石家庄 & 0.055 & 0.076 & 0.061 & 0.808 \\
杭州 & 0.033 & 0.042 & 0.072 & 0.853 & 上海 & 0.033 & 0.041 & 0.034 & 0.892 \\
合肥 & 0.052 & 0.093 & 0.124 & 0.731 & 沈阳 & 0.012 & 0.014 & 0.031 & 0.943 \\
青岛 & 0.011 & 0.067 & 0.069 & 0.853 & 太原 & 0.041 & 0.053 & 0.065 & 0.841 \\
呼和浩特 & 0.032 & 0.039 & 0.082 & 0.847 & 乌鲁木齐 & 0 & 0 & 0 & 1.000 \\
长春 & 0.012 & 0.014 & 0.013 & 0.961 & 西安 & 0.012 & 0.087 & 0.085 & 0.816 \\
宁波 & 0.026 & 0.038 & 0.065 & 0.871 & 重庆 & 0.017 & 0.045 & 0.017 & 0.921 \\
昆明 & 0.011 & 0.012 & 0.028 & 0.949 & 西宁 & 0.012 & 0.014 & 0.012 & 0.962 \\
兰州 & 0.018 & 0.021 & 0.029 & 0.932 & 郑州 & 0.063 & 0.081 & 0.123 & 0.733 \\
长沙 & 0.017 & 0.096 & 0.135 & 0.752 & & & & \\
\hline
\end{tabular}

注:表中数值为各中心城市相应市场区航线运行频次占地区航线(国内)运行总频次的比重。 
出行获取的效用最大, 也是航空线路密集分布的区 域。 $85 \%$ 的中心城市该区域航空运行频次占比达 $80 \%$ 以上, $39 \%$ 的中心城市(北京、成都、贵阳、深圳 等)该区域航空运行频次占比达 $90 \%$ 以上, 是开展航 空运输的重要市场。然而, 统计还发现许多中心城 市在该区域范围内存在明显的航空运输市场空白 (表 5), 其中西部的西宁未通航城市数量最多, 达 11 个, 长春、宁波、石家庄未通航城市数量也均在 5 个 及以上, 其余中心城市也存在 1 3 个未通航城市。 如何充分利用航空运输的绝对优势, 逐步完善相关 区域的市场空白, 对于 2 个节点城市间的互动交往 具有重要推动作用。

综合高铁、航空客运市场现实发展状况, 以及 基于旅行者交通出行选择偏好下的各市场区航空 运行班次占比情况来看: 中国中部地区尤其是中原 和长江中游地区是开展高铁运输的重要优势区域, 但目前在高铁绝对优势区、竞争激烈区、相对优势 区范围内航空运行班次占比仍较高, 是中国目前高 铁、航空运输市场竞争的主要区域; 处于周边的中 心城市, 相对偏远的区位条件使得该区域旅行者对 航空出行的需求相对较高, 高铁出行只是局限于周 边城市, 是开展航空运输的优势区域。而对于中国 东部沿海中心城市而言, 高铁、航空出行需求均较 高, 与中部地区中心城市相比, 高铁绝对优势区、竞 争激烈区、相对优势区范围内航空班次占比较低, 属于快速交通体系构建相对较好的区域。

\section{4 结论与建议}

运用标准差椭圆和交通综合效用分析方法, 对
中国中心城市高铁、航空客运市场实际发展现状及 空间竞合分异特征进行分析。结果发现:

中国高铁、航空客运市场均基本形成以武汉为 重心点的空间发展格局, 东部沿海地区快速交通网 络发展明显好于中西部地区, 与高铁客运市场相 比, 航空客运市场区域发展更加均衡; 与东西部中 心城市相比, 中部中心城市高铁运输优势明显高于 航空运输。

人均时间价值与高铁优势距呈反比, 人均时间 价值的不同使得各中心城市高铁、航空客运市场范 围存在明显的空间分异特征;一至四档所涉及中心 城市高铁出行优势距分别在 780、893、912、998 km 左右。

高铁对航空客运市场的影响存在明显的空间 分异特征。中部大部分中心城市受影响最大, 是协 调高铁、航空发展的关键区域; 西部地区受交通区 位条件及高铁发展滞后的影响,航空运输占主导地 位; 在航空绝对优势区依旧存在一定的市场空白。

基于以上发现, 提出以下几点对策建议: 各中 心城市(尤其是中部地区)应该适度压缩或者淘汰部 分中短途航线,整合城际航班,用高铁替代部分中 短途航线; 航空公司应降低航空出行成本, 简化安 检、登机流程, 提高航空出行准点率, 提高上座率; 加强高铁与航空 2 种交通运输方式的合作, 积极推 出 “空铁联运” 相关服务, 为旅客出行提供更加便捷 的出行服务。需要讨论的是: (1) 高铁、航空属于 2 种高端出行方式, 对满足消费层次高的群体需求具 有重要意义,基于区域人口消费层次结构探讨高 铁、航空发展中存在的问题将更贴近现实情况, 这 是下一步拟解决的关键问题。(2) 如何通过计量模

表 5 航空绝对优势区未开通航线统计

Tab.5 Statistics on unopened routes in aviation dominant area

\begin{tabular}{|c|c|c|c|c|c|}
\hline 城市 & 未通航城市 & 城市 & 未通航城市 & 城市 & 未通航城市 \\
\hline 广州 & 青岛 & 哈尔滨 & 拉萨、兰州、西宁 & 天津 & 西宁 \\
\hline 长沙 & 拉萨、石家庄 & 济南 & 拉萨 & 太原 & 西宁 \\
\hline 大连 & 拉萨、银川、西宁 & 石家庄 & 长沙、拉萨、兰州、南昌、西宁 & 武汉 & 拉萨 \\
\hline 合肥 & 长春、贵阳、拉萨 & 兰州 & 石家庄、宁波、长春 & 南宁 & 拉萨、宁波、西宁 \\
\hline 郑州 & 拉萨 & 南昌 & 拉萨、长沙、长春 & 贵阳 & 长春、西宁 \\
\hline 长春 & $\begin{array}{l}\text { 贵阳、合肥、拉萨、兰州、南昌、宁波、 } \\
\text { 银川、西宁 }\end{array}$ & 青岛 & 拉萨 & 沈阳 & 拉萨、银川、西宁 \\
\hline 呼和浩特 & 宁波、西宁 & 宁波 & 长春、呼和浩特、兰州、南宁、乌鲁木齐、西宁 & 乌鲁木齐 & 宁波、拉萨、海口 \\
\hline 西宁 & $\begin{array}{l}\text { 大连、贵阳、海口、呼和浩特、哈尔 } \\
\text { 滨、宁波、南宁、沈阳、石家庄、天津、 } \\
\text { 太原 }\end{array}$ & & & & \\
\hline
\end{tabular}


型构建模拟 2 种交通方式协同发展的实施路径, 对 于构建一体衔接的快速客运网络具有重要意义, 这 是进一步需突破的方向。(3) 2 种交通方式竞争最 主要的体现是区间段高铁、航空通勤频次下降或取 消, 如何获取长时间段各地区之间高铁、航空通勤 频次的变化来探讨两者间相互影响, 是该研究亟需 解决的问题。(4) 不同城市在航空、高铁站点购票、 安检、候车等过程中耗费的时间不同; 与高铁相比, 航空运输有一定的特殊性, 如折扣票、准点率等问 题,这均是该领域未来研究需着重完善的问题。

\section{参考文献(References)}

丁金学, 金风君, 王姣娥, 等. 2013. 高铁与民航的竞争博亦 及其空间效应: 以京沪高铁为例 [J]. 经济地理, 33(5): 104-110. [Ding J X, Jin F J, Wang J E, et al. 2013. Competition game of high-speed rail and civil aviation and its spatial effect: A case study of Beijing-Shanghai high-speed rail. Economic Geography, 33(5): 104-110. ]

方叶林, 黄震方, 陈文娣, 等. 2013. 2001-2010年安徽省县 域经济空间演化 [J]. 地理科学进展, 32(5): 831-839.

[Fang Y L, Huang Z F, Chen W D, et al. 2013. Spatial evolution of county economy in Anhui Province during 20012010. Progress in Geography, 32(5): 831-839. ]

郭春江. 2010. 高速铁路与民航客运量分担博亦模型研究 [D]. 北京: 北京交通大学. [Guo C J. 2010. Research on the game theoretical model of passenger traffic sharing between high speed railway and civil aviation. Beijing, China: Beijing Jiaotong University. ]

郭建科, 王绍博, 李博, 等. 2016. 哈大高铁对东北城市旅游 经济联系的空间影响 [J]. 地理科学, 36(4): 521-529. [Guo J K, Wang S B, Li B, et al. 2016. The spatial effect of Harbin-Dalian high-speed rail to the northeast city tourism economic link. Scientia Geographica Sinica, 36(4): 521529. ]

蒋海兵, 祁毅, 李传武. 2018. 中国城市高速铁路客运的空间 联系格局 [J]. 经济地理, 38(7): 26-33. [Jiang H B, Qi Y, Li C W. 2018. China's city high-speed rail (HSR) passenger spatial linkage pattern and its influence factors. Economic Geography, 38(7): 26-33. ]

梁雪松. 2010. 基于双重区位空间的湖南旅游业发展机遇探 讨: “武广高铁”开通视阈 [J]. 经济地理, 30(5): 859-864. [Liang X S. 2010. Disscussion on the development opportunity of tourism industry in Hunan Provience based on the dual locational space-the opening visual threshold of "WuGuang high speed railway". Economic Geography, 30(5): 859-864. ]

孟德友, 冯兴华, 文玉钊. 2017. 铁路客运视角下东北地区城
市网络结构演变及组织模式探讨 [J]. 地理研究, 36(7): 1339-1352. [Meng D Y, Feng X H, Wen Y Z. 2017. Urban network structure evolution and organizational pattern in Northeast China from the perspective of railway passenger transport. Geography Research, 36(7): 1339-1352. ]

彭峥, 胡华清. 2009. 高速铁路对航空运输市场的影响分析 [J]. 综合运输, (7): 70-75. [Peng Z, Hu H Q. 2009. Analysis of impact of high-speed railway on air transport market. Comprehensive Transportation, (7): 70-75. ]

卢婉婉. 2015. 高速铁路与民航的竞争博弯研究 [D]. 北京: 北京交通大学. [Lu W W. 2015. The competition game of high speed railway and civil avition. Beijing, China: Beijing Jiaotong University. ]

骆嘉琪, 医海波, 冯涛, 等. 2019. 基于两阶段博亦模型的高 铁民航竞合关系研究 [J]. 系统工程理论与实践, 39(1): 150-164. [Luo J Q, Kuang H B, Feng T, et al. 2019. Research on the co-opetition between high speed rail and civil aviation based on two stage game model. System Engineering Theory and Practice, 39(1): 150-164. ]

孙枫, 汪德根, 牛玉. 2017. 高速铁路与汽车和航空的竞争格 局分析 [J]. 地理研究, 36(1): 171-187. [Sun F, Wang D G, Niu Y. 2017. Competition patterns of high-speed rail versus highways and aviation. Geographical Reseach, 36(1): 171-187. ]

王姣娥, 胡浩. 2013. 中国高铁与民航的空间服务市场竞合 分析与模拟 [J]. 地理学报, 68(2): 175-185. [Wang J E, Hu H. 2013. Competition and cooperation of high-speed rail and air transport in China: A perspective from spatial service market view. Acta Geographica Sinica, 68(2): 175-185. ]

王绍博, 郭建科. 2016. 中国风景名胜区交通可达性及市场 潜力空间测度 [J]. 地理研究, 35(9): 1714-1726. [Wang S B, Guo J K. 2016. Spatial measure of traffic accessibility and market potential of the national scenic areas. Geographical Research, 35(9): 1714-1726. ]

王绍博, 郭建科. 2017. 我国城市整体交通运输流发展的时 空演化及其空间关联性分析 [J]. 干旱区资源与环境, 31 (2): 43-49. [Wang S B, Guo J K. 2017. Spatial and temporal evolution and spatial correlation analysis of the transportation development in China. Journal of Arid Land resources and Environment, 31(2): 43-49. ]

王绍博, 罗小龙, 郭建科, 等. 2019. 高铁网络化下东北地区 旅游空间结构动态演变分析 [J]. 地理科学, 39(4): 568577. [Wang S B, Luo X L, Guo J K, et al. 2019. Dynamic evolution of tourism spatial structure under the improvement of the high speed rail network in Northeast China. Scientia Geographica Sinica, 39(4): 568-577. ]

徐广岩. 2016. 高速铁路动车组列车客座率预测及盈亏分析 [D]. 北京: 北京交通大学. [Xu G Y. 2016. High speed 
train load factor forecast and breakeven analysis. Beijing, China: Jiaotong University. ]

钟业喜, 黄洁, 文玉钊. 2015. 高铁对中国城市可达性格局的 影响分析 [J]. 地理科学, 35(4): 387- 395. [Zhong Y X, Huang J, Wen Y Z. 2015. Impact of high-speed railway on spatial pattern of Chinese cities'accessibility. Scientia Geographica Sinica, 35(4): 387-395. ]

宗芳, 隽志才, 张慧永, 等. 2009. 出行时间价值计算及应用 研究 [J]. 交通运输系统工程与信息, 9(3): 114- 119 . [Zong F, Juan Z C, Zhang H Y, et al. 2009. Calculation and application of value of travel time. Journal of Transportation Systems Engineering and Information Technology, 9 (3): 114-119. ]

Cheng Y H. 2009. High-speed rail in Taiwan: New experience and issues for future development $[\mathrm{J}]$. Transport Policy, 10: $1-13$.

Concepción R, Raquel E, Juan C M. 2007. Competition of high-speed train with air transport: The case of MadridBarcelona [J]. Journal of Air Transport Management, 13 (5): 277-284.
Frédéric D. 2011. High-speed rail and air transport competition in Western Europe: A supply-oriented perspective [J]. Transport policy, 18(6): 870-879.

Givoni M. 2006. Development and impact of the modern highspeed train: A review [J]. Transport Reviews, 26: 593-611.

Oskar Fröidh. 2008. Perspectives for a future high-speed train in the Swedish domestic travel market [J]. Journal of Transport Geography, 16(4): 268-277.

Park Y, Ha H K. 2006. Analysis of the impact of high-speed railroad service on air transport demand $[\mathrm{J}]$. Transportation Research, 42(2): 96-140.

Vickerman R.1997. High speed rail in Europe: Experience and tissues for future development [J]. Annals of Regional Science, 31: 21-38.

Yang H, Burghouwt G, Wang J, et al. 2018. The implications of high-speed railways on air passenger flows in China [J]. Applied Geography, 97(8): 1-8.

Yang H, Dobruszkes F, Wang J, et al. 2018. Comparing China's urban systems in high-speed railway and airline networks [J]. Journal of Transport Geography, 68(4): 233-244.

\title{
Spatial differentiation of the impact of high-speed rail on aviation passenger market in central cities of China
}

\author{
WANG Shaobo ${ }^{1}$, GUO Jianke ${ }^{2 *}$, LUO Xiaolong ${ }^{1}$, GU Zongni ${ }^{1}$ \\ (1. School of Architecture and Urban Planning, Nanjing University, Nanjing 210093, China;
}

2. Center for Studies of Marine Economy and Sustainable Development, Liaoning Normal University, Dalian 116029, Liaoning, China)

\begin{abstract}
The spatial differentiation characteristics of the impact of high-speed rail on China's air passenger market is of important reference value for the coordinated development of the two modes of transportation. Using the standard deviation ellipse and traffic comprehensive utility analysis methods, this study analyzed the development status and spatial competition of the high-speed rail and air passenger transport market. The results show that: 1) The high-speed rail and aviation passenger markets have all formed a spatial pattern with Wuhan as the center. Compared with the high- speed rail, the development of the air passenger market area is more balanced; compared with the central cities of the eastern and western regions, the probability of passengers traveling with high-speed rail in the central cities of central China is higher. 2) The per capita time value is inversely proportional to the superiority distance of high-speed rail. The difference in superiority distance makes the high-speed rail and aviation passenger markets in central cities clearly different spatially. Based on the comprehensive utility perspective of traffic, for travels between most central cities in China, air travel is still the best choice. 3) The impact of high- speed rail on the air passenger transport market shows clear spatial differentiation. Most of the central cities in central China are the most affected, which is a key area for coordinating the development of high-speed railways and aviation. In the western region, due to the location conditions of transportation and the lagging development of high-speed rail, air transportation is dominant, and there is still a market gap in the aviation-dominated areas.
\end{abstract}

Keywords: high-speed rail; aviation; per capita time value; competition and cooperation; spatial differentiation 